\title{
Celiac disease and functional abdominal pain disorders: Are they the same? A literature review
}

\author{
Enfermedad celíaca y trastornos funcionales del dolor abdominal: ¿son lo mismo? \\ Revisión de la literatura
}

Ana C. Falcon*

Department of Pediatric Gastroenterology, Hepatology, and Nutrition, University of Miami Miller School of Medicine, Miami, FL, USA

\begin{abstract}
Approximately one in three children complain of abdominal pain weekly; between 3 and $7 \%$ of all children with abdominal pain are referred to gastroenterologists. Celiac disease (CD), a common immune-mediated inflammatory disease of the small intestine, is usually suspected; while functional abdominal pain disorders (FAPDs) characterized by an abnormally elevated sensibility to pain, are the cause of more than half of all consultations. CD can mimic FAPDs, making both conditions difficult to distinguish clinically. A potential overlap of FAPDs and CD constitutes another conflict for the long-term treatment of patients with either or both diagnoses. This literature review has the objective to educate on how to distinguish both conditions, considering they have different management, treatment and consequences on the patient's quality of life. Early differentiation and diagnosis will prove to be beneficial to the patient itself and their families that tend to be subject to prolonged testing.
\end{abstract}

Key words: Celiac disease. Functional abdominal paid disorders. Abdominal pain. Children. Pediatric gastroenterologists. Testing.

\section{RESUMEN}

Aproximadamente, cada semana 1 de cada 3 niños se queja de dolor abdominal; entre 3 y $7 \%$ de todos los niños con dolor abdominal son referidos a gastroenterólogos. La enfermedad celíaca (CD por sus siglas en inglés) es una enfermedad inflamatoria común del intestino delgado la cual suele ser sospechada como causante principal del dolor abdominal; mientras que los trastornos funcionales de dolor abdominal (FAPDs por sus siglas en inglés) caracterizados por una sensibilidad anormal elevada al dolor, es la causa de más de la mitad de todas las consultas. La enfermedad celíaca puede parecerse a los FAPDs, haciendo difícil la diferenciación entre ambas condiciones. Una posible sobreposición entre FAPDs y CD constituye otro conflicto para el tratamiento a largo plazo de pacientes con uno o ambos diagnósticos. Esta revisión de la literatura tiene el objetivo de educar sobre cómo distinguir ambas condiciones, considerando que tienen diferente manejo, tratamiento y consecuencias en la calidad de vida de los pacientes. La pronta diferenciación y diagnóstico adecuado será beneficioso tanto para el paciente, como para sus familias quienes tienden a ser sujetas a múltiples evaluaciones.

Palabras clave: Enfermedad celíaca. Trastornos funcionales de dolor abdominal. Dolor abdominal. Niños. Gastroenterología pediátrica.

Correspondence to:

*Ana C. Falcon

E-mail: anacorinafalcon@gmail.com
NeuroGastroLatam Rev. (ahead of print)

Received in original form: 08-04-2021

Accepted in final form: 20-05-2021

DOI: 10.24875/NGL.210000091

2462-7011/C 2021 Sociedad Latinoamericana de Neurogastroenterología, A.C. Published by Permanyer. This is an open access article under the CC BY-NC-ND license (http://creativecommons.org/licenses/by-nc-nd/4.0/). 


\section{INTRODUCTION}

Approximately one in three children complains of abdominal pain weekly. Twentyfour percent of all children report abdominal pain lasting for at least 8 weeks ${ }^{1}$. Between 3 and $7 \%$ of all children with abdominal pain are referred to gastroenterologists who are generally inclined to perform numerous tests looking for an organic cause to their symptoms. One of the most common soughs after causes is celiac disease (CD), a common immune-mediated inflammatory disease of the small intestine caused by sensitivity to dietary gluten and related proteins in genetically predisposed individuals. However, a subset of children with chronic abdominal pain, present with what is known as functional abdominal pain disorders (FAPDs), characterized by an abnormally elevated sensibility to pain, as well as increased central perception of visceral stimuli leading to disability ${ }^{2}$. CD can mimic Irritable Bowel Syndrome (IBS), a type of FAPD, making both conditions difficult to distinguish clinically ${ }^{3}$ (Table 1). In contrast to $C D$, where serological markers such as tissue transglutaminase-immunoglobulin A (IgA) antibodies and anti-endomysial-IgA antibody are likely to be elevated ${ }^{4}$, the lack of biochemical markers to objectively diagnose or monitor the progression of FAPDs, makes their diagnosis a true challenge.

This literature review has the objective to educate on how to distinguish both conditions, considering they have different management, treatment and consequences on the patient's quality of life. Early differentiation and diagnosis will prove to be beneficial to the patient itself and their families that tend to be subject to prolonged testing. Such extended testing occurs after the last version of the Rome criteria (ROME IV) recommends that all children with IBS-like symptoms undergo serologic testing for $\mathrm{CD}$. This recommendation was based on a prospective cohort study conducted in Italy that found a four-fold higher prevalence of biopsy-proven $\mathrm{CD}$ among pediatric patients with symptoms suggestive of IBS, compared with healthy controls $^{5}$. However, there is controversy on whether these recommendations should be applied universally. A study conducted in a predominantly Latino sample, found that the prevalence of CD in children with FAPDs was similar to the expected prevalence in the community ${ }^{6}$. Although the debate on whether CD testing is needed has not been solved, it is likely that a thorough physical examination, could lead to early diagnosis and avoidance of unnecessary testing in patients presenting with the common denominator of the above-mentioned conditions: chronic abdominal pain.

\section{WHAT ARE FAPDs?}

Functional gastrointestinal disorders, in general, are some of the most commonly encountered disorders in childhood, affecting up to $25 \%$ of all children and infants 7 . In 2015, meta-analysis of 58 studies including 196,472 children worldwide, the pooled prevalence of FAPDs was $13.5 \%$ (95\% 11.8-15.3) $)^{8}$. They are associated with functional disability, impaired quality of life, and a cost burden on healthcare?.

Pediatric FAPDs are subclassified utilizing the Rome IV criteria into a number of 
TABLE 1. Signs and symptoms may overlap between CD and FAPDs according to ROME IV

\begin{tabular}{|l|c|c|c|c|c|} 
& Celiac disease & Irritable bowel syndrome & Dyspepsia & Abdominal migraine & FAPDs-NOS \\
\hline Symptoms & & & & $X$ & $X$ \\
Abdominal Pain & $X$ & $X$ & $X$ & $X$ \\
Nausea & $X$ & $X$ & & $X$ \\
Diarrhea & $X$ & $X$ & $X$ & $X$ \\
Constipation & $X$ & $X$ & $X$ \\
Bloating & $X$ & & \\
\end{tabular}

clinically distinct entities, namely, IBS, functional dyspepsia, abdominal migraine, and functional abdominal pain not otherwise specified (FAP-NOS) ${ }^{10}$.

\section{Types of FAPDs}

1. IBS is a gastrointestinal disorder characterized by chronic abdominal pain and altered bowel habits. It is the most commonly diagnosed FAPD and accounts for approximately $30 \%$ of all referrals to gastroenterologists ${ }^{11}$. The pathophysiology of IBS remains uncertain ${ }^{12}$. Abdominal pain in IBS can be associated with defecation or a change in the frequency or form of the stool but does not resolve with resolution of associated constipation ${ }^{13}$.

2. Functional dyspepsia describes a symptom profile from the proximal gastrointestinal tract involving epigastric abdominal pain and/or bothersome postprandial fullness and/or early satiation. Dyspepsia is characterized by pain or discomfort that is centered in the epigastric region or upper abdomen. Discomfort may be characterized by fullness, early satiety, bloating, nausea, retching, or vomiting. The pain or discomfort may be exacerbated by eating ${ }^{10}$.
3. Abdominal migraine is characterized by the presence of paroxysmal prolonged episodes of intense, acute periumbilical, midline, or diffuse abdominal pain. These painful episodes are typically incapacitating and interfere with normal activities and occur in a stereotypical pattern (i.e.in a set form or pattern, example.g. with regard to the presence or form of aura and the escalation of symptoms, severity, and frequency) for the individual patient. The episodes are often but not always associated with other symptoms (such as anorexia, nausea, vomiting, headache, photophobia, and pallor), which might precede or coincide with the duration of pain, and such symptomatic episodes may be separated by weeks to months ${ }^{2}$.

4. FAP-NOS accounts for episodic or continuous abdominal pain that does not occur solely during physiological events and does not meet criteria for the other FA$\mathrm{PDs}^{10}$.

\section{Diagnosis and clinical presentation of FAPDs}

The diagnosis of FAPDs is primarily based on clinical symptoms and exclusion of other 
organic causes, with an emphasis on avoiding unnecessary invasive diagnostic procedures. In most cases, only a detailed patient history and thorough physical examination are needed to establish FAPD diagnosis, and to provide effective reassurance of the benign nature of the disease. The key elements in patient history include elucidating the characteristics of the pain, including location, quality, severity, duration, factors (especially food) that trigger or alleviate it, and its occurrence during sleep; as well as excluding potential red flags such as involuntary weight loss or loose stools with blood ${ }^{2}$. Children with FAPDs may be as functionally disabled as children with organic diseases such as inflammatory bowel disease (IBD) ${ }^{14}$.

\section{Treatment}

Pharmacological targets include prokinetics and drugs affecting gastric accommodation to treat postprandial distress and nausea. Similarly, anti-inflammatory agents, junctional protein regulators, analgesics, secretagogues, and serotonin antagonists have a therapeutic role for IBS. Non-pharmacological treatments include peripheral electrical nerve field stimulation to the external ear, gastric electrical stimulation, and dietary interventions such as low fructose and fiber-based diets, and nutraceuticals, which include probiotics, prebiotics, and symbiotic. Newer psychological advances such as exposure-based cognitive behavioral therapy, acceptance and commitment therapy, and mindfulness meditation are being investigated for pediatric functional pain. Finally, alternative therapies such as acupuncture, moxibustion, yoga, and spinal manipulation are also gaining popularity in the treatment of FAPDs ${ }^{15}$.

The available pharmacological interventions are limited in children and, therefore, management has focused on combined approaches, including mind-targeted interventions (hypnotherapy and cognitive behavioral therapy), diet (probiotics), and percutaneous electrical nerve field stimulation. The evidence for their clinical efficacy, although limited, is favorable, with positive impacts on symptoms and overall quality of life ${ }^{2}$.

\section{WHAT IS CD AND HOW COMMON IS IT?}

$\mathrm{CD}$ is an immune-mediated inflammatory disease of the small intestine caused by sensitivity to dietary gluten and related proteins in genetically sensitive individuals. The grains that contain the triggering proteins are wheat, barley, and rye. Ingestion of these proteins by a susceptible individual causes immune-mediated mucosal inflammation of the proximal small intestine, with villous atrophy and crypt hyperplasia which often leads to malabsorption and gastrointestinal symptoms ${ }^{16}$.

The disorder is a common chronic condition and is estimated to affect approximately 0.5$1 \%$ of the general population. In Europe, the United States, and Australia, the prevalence estimates range from 1:80 to 1:300 children ( 3 to 13 per 1000 children) ${ }^{16}$. A large serologic screening study in the United States suggested a prevalence of 1:133 among patients with no risk factors or symptoms ${ }^{17}$. Females are affected approximately twice as often as 
males, although the ratio varies depending on the strategy used to find cases ${ }^{18}$.

The prevalence of $\mathrm{CD}$ as detected by screening programs using specific antibodies is substantially increased in first- and second-degree relatives of patients with CD and in individuals with Down syndrome, type 1 diabetes mellitus, selective IgA deficiency, autoimmune thyroid disease, and probably Turner and Williams syndromes. For these groups, the risk of $\mathrm{CD}$ is approximately 3-10-fold higher than in the general population $^{17}$.

\section{WHAT ARE THE SYMPTOMS OF CD?}

In the past, $\mathrm{CD}$ was thought to mainly present in infants between 6 and 24 months of age (classical form), after the introduction of gluten into the diet ${ }^{19}$. Now, CD tends to present later, between the ages of 10 and 40, with milder gastrointestinal or non-gastrointestinal manifestations ${ }^{20}$. This changing presentation of the disease may be due to the later introduction of gluten into the infant diet. Furthermore, advances in serologic screening have increasing recognition of children with atypical gastrointestinal presentation and high-risk groups with mild symptoms ${ }^{21}$.

The children may present with symptoms of malabsorption such as chronic diarrhea, steatorrhea, anorexia, abdominal distension and pain, weight loss, and failure to thrive or other signs of nutrient or vitamin deficiency. Moreover, the resolution of the clinical symptoms and mucosal lesions on withdrawal of gluten-containing foods, usually within few weeks to months strongly suggests $C D$.
Gastrointestinal symptoms in older children and adults are similar but usually less dramatic. Paradoxically, the disease may cause either constipation $(8 \%)$ or diarrhea $(64 \%)^{22}$. When diarrhea is present, the stools are often bulky and foul-smelling and may float because of trapped air. Flatulence and abdominal distension (caused by colonic bacterial digestion of malabsorbed nutrients) are common.

In some patients, non-gastrointestinal symptoms are the primary presenting complaint and should prompt the consideration of serologic testing. The most specific extraintestinal manifestation is dermatitis herpetiformis, which is uncommon before puberty.

\section{WHY IS THE EARLY DIAGNOSIS OF CD IMPORTANT?}

If the diagnosis is delayed, children may present with signs of malnutrition. Severely affected infants may present with a celiac crisis and the hemodynamic and metabolic consequences of dehydration; also, growth failure, severe anemia, neurologic disorders from deficiencies of B vitamins, osteopenia from deficiencies of Vitamin D and calcium, arthritis, dental enamel defects, and liver disease can be seen in severe cases.

As previously stated, children who develop symptomatic $\mathrm{CD}$ often have delayed linear growth. It is important to note that between 8 and $10 \%$ of children with apparent "idiopathic" short stature have serologic evidence of $\mathrm{CD}^{19}$, making it paramount to do a thorough exam of the patient and gathering a detailed clinical history. 
Adolescent girls may have an increased frequency of menstrual abnormalities such as delayed menarche and, later, may have problems with infertility and experience an early menopause $^{23}$. Boys with untreated CD have reduced levels of serum dihydrotestosterone in a pattern suggesting androgen resistance ${ }^{24}$. Treatment with a gluten-free diet appears to prevent these problems.

\section{HOW DOES FAPDs AND CD CORRELATE?}

Both FAPDs and CD tend to present with similar symptoms, being abdominal pain the most prominent one. At present, the public awareness regarding the alarm signs for CD are so well known, that not only the treating physician but also de patients, are seeking diagnostic testing and treatment whenever experiencing symptoms that might relate to those of CD.

As referred to in the introduction of this article, while CD tends to have positive serologic markers, patients with FAPDs do not count with specific markers to make the diagnosis, as such constituting a challenging diagnosis. FAPDs diagnosis can become difficult not necessarily because its a complicated pathology, more likely because it tends to depend on the doctor's experience with functional disorders whether the diagnosis is made rather sooner than later.

In both CD and FAPDs, patients might present with abdominal pain, constipation, diarrhea or an alteration of the patient's bowel movement pattern. Patients tend to have extensive diagnostic testing that can become an economic burden to the patient and their families.

In a study made by Dhroove et al., where the cost of diagnosing patients with FAPDs, the average cost of evaluating each child was $6,104.3 \$$ which represents $77 \%$ of the annual per capita health-care expenditure in the United Sates as of 2007 (being 7,900\$/capita) $)^{25,26}$. Only one out of the 64 patients with FAPDs who were screened for CD had positive celiac markers. The finding of a single case of latent CD in this sample size probably reflects the prevalence of this condition in the general population ${ }^{27}$, which is considered to be $0.5-1 \%$ in many parts of the world.

In 2016, 976 patients under 18 years of age were enrolled in a study made in a Pediatric Gastroenterology Outpatient Practice; the prevalence of IBS came out to be 52\% (172/332) in infant/toddlers; 75\% (486/644) in children and adolescents ${ }^{28}$. This shows how the prevalence of FAPDs, particularly IBS is much greater in the pediatric population than $C D$, proving once more the importance of learning how to differentiate both and in keeping in mind a potential functional diagnosis.

At present, there is controversy regarding testing strategies in patients with symptomatology suggestive of a FAPD. The debate becomes more apparent in pediatrics as there are contradictory studies resulting in recommendations that may not be applicable universally, whereas clinical guidelines for adults appear to have reached a clearer agreement.

The American College of Gastroenterology (ACG) developed clinical guidelines for the management of IBS in adults using the 
Grading of Recommendations, Assessment, Development and Evaluation methodology. It created a consensus suggesting that serologic testing be performed to rule out CD in patients with IBS and diarrhea symptoms, as well as evaluating fecal calprotectin in patients with suspected IBS and diarrhea to rule out IBD $^{29}$.

In the pediatric sphere, the latest version of the Rome Criteria (ROME IV) recommends that all children with IBS-like symptoms undergo serologic testing for CD. This came after a study in Italy found a 4-times increased prevalence of CD proven by biopsy, among pediatric patients with IBS, compared with healthy controls ${ }^{5}$. Conversely, another study made by the University of Miami in a Latino predominant sample found the prevalence of CD in children with FAPDs to be similar to the prevalence in the general community ${ }^{6}$.

\section{WHAT HAPPENS AFTER PROPER DIAGNOSIS? CAN CD AND FAPDs OVERLAP?}

After patients have been thoroughly examined and a diagnosis is made, another set of challenges become apparent. A handful of studies have revealed the potential overlap between IBD and CD with FAPDs, proposing that inflammation of the gut (infectious and non-infectious) predisposes children to the development of visceral hypersensitivity that can manifest as FAPDs, including $\mathrm{IBS}^{30}$. Studies suggest that the overlap between FAPDs and IBS is more common in adults than in children, yet the causes for these differences in the prevalence are unknown.
Furthermore, a new question is posed, centering its hypothesis in the fact that if inflammation of the gut can evolve into FAPDs (post-infectious IBS), then organic diseases that chronically produce an intestinal inflammation, such as CD might then have the same impact.

The new onset of IBS symptoms in patients with an underlying organic disease, such as $\mathrm{CD}$, presents another obstacle that must be overcome for the better of the patient. It becomes clinically challenging to define the real cause of the patient's symptomatology, given that the same presentation may represent a flare-up of the CD or an overlapping FAPD. Likewise, IBS symptoms in a child with CD may occur due to poorly controlled diet or the overlap with a FAPD. This becomes a clinical problem relevant to pediatric gastroenterologists, due to the fact that children with diagnosed CD and who follow a gluten-free diet, sometimes still present with abdominal pain, making the management a difficult one ${ }^{30}$.

Although there is little research on the overlap of FAPDs with organic diseases in children, in 2013, Saps et al. conducted a retrospective study to assess whether patients with CD are more likely than controls to develop abdominal pain and a FAPD in longterm follow-up. The control group was composed of siblings or cousins of patients with $C D$ in the case group. They hypothesized that children with CD would be at higher risk of developing FAPDs. Results showed that children with acute gastroenteritis had a $>$ 3-fold risk of developing FAPDs including IBS (post-infectious IBS) and functional dyspepsia; however, no statistically significant differences in abdominal pain and 
development of a FAPDs were found between the case group with CD and control group, comprised of the sibling or cousins of patients in the case groups ${ }^{31}$.

Conversely, a group in Italy conducted a prospective cohort study posing the same hypothesis; enrolling 417 patients with a diagnosis of CD, who had been on a strict gluten-free diet for more than 1 year and had negative results from serologic tests after being on such diet. They found a higher prevalence of FAPDs among patients with CD than controls. IBS and functional constipations were more prevalent in patients with CD than controls $^{32}$.

\section{DISCUSSION}

FAPDs are a common gastrointestinal set of pathologies seen in children, often misdiagnosed and overseen by pediatricians and gastroenterologists worldwide; although in the US, more than half of all consultations to tertiary care pediatric gastroenterology clinics are related to FAPDs ${ }^{33}$. Being abdominal pain a symptom reported by $24 \%$ of all children, and the high expense associated with diagnosing functional disorders, it has become evident the need for a cost-effective approach that will help alleviate the current situation where patients and their families more often than not, get frustrated for the lack of a definitive diagnosis and the multiple testing they tend to be subjected to.

At present, information regarding organic gut pathologies such as CD or IBD are so well know, practitioners and patients alike, tend to lean toward a diagnosis of the abovementioned diseases; rather than to explore other options that might be diagnosed without the need of extensive testing. However, the lack of definitive serologic markers that will prove the existence of FAPDs makes the diagnosis a challenging one since both CD and FAPDs present with a common a predominant symptom: chronic abdominal pain.

It can become clinically difficult to differentiate both as not only they share the presence of abdominal pain but also diarrhea or constipation as well, bloating, nausea, and other common reported symptoms in children. In consequence, physicians must be trained in functional disorders as they are in organic diseases of the gut, to be able to provide an early diagnosis after a thorough physical examination.

At present, the pediatric medical community through the ROME IV committee recommends testing all children with IBS-suggestive symptoms for CD; however, such recommendations might not be in fact applicable universally, since they were made after a single study that found a higher prevalence of $C D$ in patients with IBS. Moreover, the ACG'S clinical guidelines for management of IBS in adults have reached a general consensus suggesting serologic testing to be performed in all patients with IBS and diarrhea to rule out CD.

One last challenge lies ahead after proper diagnosis of $\mathrm{CD}$ is done: the possibility of a FAPDs overlapping with CD. There have been cases where children following a strict gluten-free diet present with recurring abdominal pain that does not subside once eating habits are changed. Such clinical presentation 
prompted studies in the US and Europe, evaluating whether patients with $C D$ are more likely than controls to develop FAPDs and abdominal pain long-term. Unfortunately, while studies in Italy proved the hypothesis of patients with $C D$ to have an increased risk of developing FAPDs, the US studies found no statistically significant difference between cases and controls subjects.

Seeing these contradictory results, it becomes clear how larger scale studies including clinical trials and possibly laboratory models are necessary. Wider cohorts of children analyzed in a prospective fashion would expand our knowledge about the relation between organic bowel diseases and FAPDs. It would also help to better understand the risk factors involved in the development of functional disorders and how to properly treat them.

\section{CONCLUSIONS}

A potential overlap of FAPDs and CD constitutes another conflict for the long-term treatment of patients with either or both diagnoses. There is only a handful of studies conducted to address this presentation and unfortunately the results are contradictory. FAPDs are widely present in pediatric patients, commonly presented as IBS with chronic abdominal pain with alternating consistency and frequency of bowel movements. Such symptomatology can also be seen in $\mathrm{CD}$, making the differentiation a clinical challenge for pediatricians.

It is of utmost importance for physicians to be on the look-out for potential symptoms that might indicate a functional diagnosis rather than an organic one; providing patients with a rapid diagnosis that will potentially improve their quality of life and save them the need of spending large sums of money in unnecessary testing and medical consultations.

Moreover, it seems imperative to further study patients with organic bowel pathologies such as IBD and CD in the long-term, to determine if in fact they are at high risk of developing FAPDs. This will greatly help to understand the overlap and improve the management of such patients.

\section{FUNDING}

The author received no specific funding for this work.

\section{CONFLICTS OF INTEREST}

The author declares that there are no conflicts of interest.

\section{ETHICAL DISCLOSURES}

Protection of human and animal subjects. The author declares that no experiments were performed on humans or animals for this study.

Confidentiality of data. The author declares that no patient data appear in this article.

Right to privacy and informed consent. The author declares that no patient data appear in this article. 


\section{REFERENCES}

1. Saps M, Seshadri R, Sztainberg M, Schaffer G, Marshall BM, di Lorenzo C. A prospective school-based study of abdominal pain and other common somatic complaints in children. J Pediatr. 2009;154:322-6.

2. Thapar N, Benninga MA, Crowell MD, di Lorenzo C, Mack I, Nurko S, et al. Paediatric functional abdominal pain disorders. Nat Rev Dis Primers. 2020;6:89.

3. Sanders DS, Carter MJ, Hurlstone DP, Pearce A, Ward AM, McAlindon ME, et al. Association of adult coeliac disease with irritable bowel syndrome: a case-control study in patients fulfilling ROME II criteria referred to secondary care. Lancet. 2001;358:1504-8.

4. Gidrewicz D, Potter K, Trevenen CL, Lyon M, Butzner JD. Evaluation of the ESPGHAN celiac guidelines in a North American pediatric population. Am J Gastroenterol. 2015;110:760-7.

5. Cristofori F, Fontana C, Magistà A, Capriati T, Indrio F, Castellaneta S, et al. Increased prevalence of celiac disease among pediatric patients with irritable bowel syndrome: a 6-year prospective cohort study. JAMA Pediatr. 2014;168:555-60.

6. Falcon AC, Fifi AC, Fernandez-Valdes L, Jaquez J, Mariaud C, Saps M. Is celiac disease testing necessary in functional abdominal disorders? A study in predominantly Latino children. J Pediatr Gastroenterol Nutr. 2020;72: $542-5$.

7. Robin SG, Keller C, Zwiener R, Hyman PE, Nurko S, Saps M, et al. Prevalence of pediatric functional gastrointestinal disorders utilizing the Rome IV criteria. J Pediatr. 2018;195:134-9.

8. Korterink JJ, Diederen K, Benninga MA, Tabbers MM. Epidemiology of pediatric functional abdominal pain disorders: a meta-analysis. PLoS One. 2015;10:e0126982.

9. Cunningham NR, Moorman E, Brown CM, Mallon D, Chundi PK, Mara CA, et al. Integrating psychological screening into medical care for youth with abdominal pain. Pediatrics. 2018;142:e20172876.

10. Hyams JS, di Lorenzo C, Saps M, Shulman RJ, Staiano A, van Tilburg M. Functional disorders: children and adolescents. Gastroenterology. 2016;16:181-5.

11. Drossman DA, Camilleri M, Mayer EA, Whitehead WE. AGA technical review on irritable bowel syndrome. Gastroenterology. 2002;123:2108-31.

12. Camilleri M. Peripheral mechanisms in irritable bowel syndrome. N Engl J Med. 2012;367:1626-35.

13. Rajindrajith S, Devanarayana NM. Subtypes and symptomatology of irritable bowel syndrome in children and adolescents: a school-based survey using Rome III criteria. J Neurogastroenterol Motil. 2012;18: 298-304.

14. Youssef NN, Murphy TG, Langseder AL, Rosh JR. Quality of life for children with functional abdominal pain: a comparison study of patients' and parents' perceptions. Pediatrics. 2006;117:54-9.

15. Santucci NR, Saps M, van Tilburg MA. New advances in the treatment of paediatric functional abdominal pain disorders. Lancet Gastroenterol Hepatol. 2020;5:316-28.
16. Gujral N, Freeman HJ, Thomson AB. Celiac disease: prevalence, diagnosis, pathogenesis and treatment. World J Gastroenterol. 2012;18:6036-59.

17. Fasano A, Berti I, Gerarduzzi T, Not T, Colletti RB, Drago S, et al. Prevalence of celiac disease in at-risk and not-at-risk groups in the United States: a large multicenter study. Arch Intern Med. 2003;163:286-92.

18. Lanzini A, Villanacci V, Apillan N, Lanzarotto F, Pirali F, Amato M, et al. Epidemiological, clinical and histopathologic characteristics of celiac disease: results of a case-finding population-based program in an Italian community. Scand J Gastroenterol. 2005;40:950-7.

19. Hill ID, Dirks MH, Liptak GS, Colletti RB, Fasano A, Guandalini S, et al Guideline for the diagnosis and treatment of celiac disease in children: recommendations of the North American society for pediatric gastroenterology, hepatology and nutrition. J Pediatr Gastroenterol Nutr. 2005;40:1-19.

20. Khatib M, Baker RD, Ly EK, Kozielski R, Baker SS. Presenting pattern of pediatric celiac disease. J Pediatr Gastroenterol Nutr. 2016;62:60-3.

21. McGowan KE, Castiglione DA, Butzner JD. The changing face of childhood celiac disease in North America: impact of serological testing. Pediatrics. 2009;124:1572-8.

22. Rashid M, Cranney A, Zarkadas M, Graham ID, Switzer C, Case S, et al. Celiac disease: evaluation of the diagnosis and dietary compliance in Canadian children. Pediatrics. 2005;116:e754-9.

23. Sher KS, Mayberry JF. Female fertility, obstetric and gynaecological history in coeliac disease: a case control study. Acta Paediatr Suppl. 1996;412:76-7.

24. Bona G, Marinello D, Oderda G. Mechanisms of abnormal puberty in coeliac disease. Horm Res. 2002;57 Suppl 2:63-5.

25. Keehan S, Sisko A, Truffer C, Smith S, Cowan C, Poisal J, et al. Health spending projections through 2017: the baby-boom generation is coming to Medicare. Health Aff (Millwood). 2008;27:w145-55.

26. Dhroove G, Chogle A, Saps M. A million-dollar work-up for abdominal pain: is it worth it? J Pediatr Gastroenterol Nutr. 2010;51:579-83.

27. Tully MA. Pediatric celiac disease. Gastroenterol Nurs. 2008;31:132-40; quiz $141-2$.

28. Rouster AS, Karpinski AC, Silver D, Monagas J, Hyman PE. Functional gastrointestinal disorders dominate pediatric gastroenterology outpatient practice. J Pediatr Gastroenterol Nutr. 2016;62:847-51.

29. Lacy BE, Pimentel M, Brenner DM, Chey WD, Keefer LA, Long MD, et al ACG clinical guideline: management of irritable bowel syndrome. Am J Gastroenterol. 2021;116:17-44.

30. Langshaw AH, Rosen JM, Pensabene L, Borrelli O, Salvatore S, Thapar N, et al. Sobreposición entre los trastornos funcionales de dolor abdominal y enfermedades orgánicas en niños. Rev Gastroenterol Méx. 2018;83:268-74.

31. Saps M, Adams P, Bonilla S, Nichols-Vinueza D. Abdominal pain and functional gastrointestinal disorders in children with celiac disease. J Pediatr. 2013;162:505-9.

32. Cristofori F, Tripaldi M, Lorusso G, Indrio F, Rutigliano V, Piscitelli D, et al Functional abdominal pain disorders and constipation in children on gluten-free diet. Clin Gastroenterol Hepatol. 2020;20:31229-5.

33. Spee LA, Lisman-van Leeuwen Y, Benninga MA, Bierma-Zeinstra SM, Berger MY. Prevalence, characteristics, and management of childhood functional abdominal pain in general practice. Scand J Prim Health Care. 2013;31:197-202. 